\title{
Irreversible Loss of Vision in a Child due to Occipital Infarction after Gastroenteritis
}

\author{
Ahmad M. Mansour ${ }^{a}$ Dana Hasbini ${ }^{b}$ Muhammad H. Younis ${ }^{a}$ \\ M. Tariq Bhattic \\ ${ }^{a}$ Department of Ophthalmology, Rafik Hariri University Hospital and American University \\ of Beirut, and ${ }^{b}$ Pediatric Neurology Service, Department of Neurology, Rafik Hariri \\ University Hospital, Beirut, Lebanon; 'Departments of Ophthalmology and Neurology, \\ Duke Eye Center and Duke University Medical Center, Durham, N.C., USA
}

\section{Key Words}

Occipital infarct · Gastroenteritis · Visual recovery

\begin{abstract}
A 21/2-year-old girl developed a bilateral occipital infarct following severe gastroenteritis with bilateral vision of light perception. Evaluations for sickle cell anemia, hemolytic anemia and coagulopathies were negative. Cortical blindness is an uncommon but dramatic complication of gastroenteritis, hence the need of prompt hydration and other supportive measures to avoid irreversible visual loss or mental sequela.

(c) 2015 S. Karger AG, Basel
\end{abstract}

\section{Introduction}

Vision is well represented in the brain. It has been estimated that visual processing areas occupy more than half of the total surface of the primate neocortex [1]. Acute profound loss of vision from occipital infarct is a devastating event to the patient and family [2-10]. Despite significant medical progress over the past several decades, cortical blindness can still affect patients of various ages due to what is believed to be a relatively benign illness. We present a very young girl with cortical blindness following rotavirus gastroenteritis. 
Mansour et al.: Irreversible Loss of Vision in a Child due to Occipital Infarction after Gastroenteritis

\section{Case Report}

This $2 \frac{1}{2}$-year-old girl was born at term after a normal pregnancy and uneventful labor. She had normal developmental milestones until she developed protracted afebrile diarrhea and vomiting for 2 days, necessitating the admission to a hospital and the insertion of an intravenous line, which was a difficult task in this dehydrated child. Her hematocrit was 15.7 with a normal electrolyte profile and positive rotavirus antigen. The girl required a blood transfusion for acute anemia during her admission to the hospital. The family history was positive for glucose-6-phosphate dehydrogenase (G6PD) deficiency. One day after hospitalization, the patient was noted to have lost her vision completely. MRI of the brain documented a bilateral occipital lobe infarction (fig. 1). She was started on steroid therapy and good hydration. A week later, her hematocrit level rose to 32. The patient continued to have light perception vision bilaterally. She made no eye contact. A fixation was absent and there was no blink response to threat. The pupillary light reflexes were normal. The fundus examination was normal and the neurological examination was nonfocal. Workup was negative for sickle cell anemia. Serum levels for antithrombin, protein S, protein C, pyruvate kinase (hemolytic anemia), G6PD, amino acids and thyroid function tests were within normal range. The working diagnosis was a hypotension-induced occipital infarct. The patient was placed on oral corticosteroid therapy for 2 months, without any change in visual acuity.

\section{Discussion}

It has been shown in a number of studies that the distribution of etiology of cerebral infarction among young patients differs from older patients. Furthermore, it has been shown that the long-term prognosis among young patients with cerebral infarction differs in terms of underlying risk factors. Occipital infarction is associated with younger age, female sex, and a prothrombotic state while extraoccipital infarction is more often associated with systemic hypertension and hypercholesterolemia [9].

Hypoxic-ischemic brain injuries are the commonest cause of cortical visual impairment in children. The resulting visual impairment relates to the age of the subject and both the severity and the duration of hypoxia [3]. Full-term infants commonly sustain injury at the watershed zones of the cerebral cortex, while premature infants have periventricular injury with little cortical damage [3]. Occipital infarction is often associated with an irreversible loss of visual perception [7]. However, unlike adults, children appear to have a better visual prognosis with a better chance for recovery. Plasticity (ability to reorganize and recover) of the child brain has been implicated in this visual recovery [3]. Bova et al. [10] described the visual recovery of a male child who had a bilateral occipital lobe infarction at the age of 2 years and 6 months, 10 days after a colon resection for Hirschsprung disease. In the acute phase, there was severe visual impairment without any visual response, but eventually, the patient recovered the ability to perceive movement, followed by the recovery of visual acuity and accompanied by a progressive reduction of the visual field defect. At 6 years and 8 months, visual recognition acuity was $20 / 20$ in both eyes, with a persistence of the visual field defect in the upper hemifield, and he was also able to see overlapping figures. According to case reports and various animal models [11], processes related to cerebral plasticity may take years to develop after a brain lesion.

In our case, systemic hypotension (hypovolemic shock) from rotavirus gastroenteritis and dehydration [12] most likely led to a decrease in blood flow (oxygen and nutrients) to a critical level, jeopardizing the occipital lobe region in the watershed area. Hemolytic anemia, 
Mansour et al.: Irreversible Loss of Vision in a Child due to Occipital Infarction after Gastroenteritis

triggered possibly by the virus infection, contributed also to the hypoxia theory herein, although we lacked laboratory documentation in our case. Watershed infarcts occur at the border zones between major cerebral arterial territories as a result of hypoperfusion. The occipital lobe is supplied most often by the posterior cerebral artery, a terminal branch of the basilar artery. Hence, occipital lobe infarcts are traditionally attributed to vertebrobasilar disease [13]. Occasionally, the occipital lobe is supplied uniquely by branches of the internal carotid disease in up to $11 \%$ of subjects [13].

Sickling crisis [5, 8] or thrombogenic risk factors (coagulation disorders) [4] can predispose children to cerebral infarcts, especially with a precipitating cause (surgical intervention, blood loss or viral illness like gastroenteritis). Management strategies include immediate hydration, correction of electrolyte imbalance, reversal of anemia, control of body temperature, oxygen administration (in case of hypoxia) and the administration of corticosteroid to decrease coexistent brain edemas from infarction. Although our patient did not show an improvement after 2 months, hope still exists that partial visual recovery will occur gradually years after the vascular event.

\section{Disclosure Statement}

The authors report no conflict of interests.

\section{References}

1 Sereno MI, Dale AM, Reppas AM, Kwong KK, Belliveau JW, Brady TJ, Rosen BR, Tootell RBH: Borders of multiple visual areas in human revealed by functional magnetic resonance imaging. Science 1995;268:889893.

-2 Aldrich M, Alessi A, Beck R, Gilman S: Cortical blindness: etiology, diagnosis and prognosis. Ann Neurol 1987;21:149-158.

-3 Hoyt CS: Visual function in the brain-damaged child. Eye 2003;17:369-384.

-4 Vagiaku EA, Voudris KA, Dimitriou Y, Skardoutsou A, Mastrovianni S: Different additional risk factors for cerebral infarctions associated with the factor V Leiden mutation in a family. J Child Neurol 2006;21:903907.

5 Webb J, Kwiatkowski JL: Stroke in patients with sickle cell disease. Expert Rev Hematol 2013;6:301-316.

-6 O'Hare AE, Dutton GN, Green D, Coull R: Evolution of a form of pure alexia without agraphia in a child sustaining occipital lobe infarction at 21/2 years. Dev Med Child Neurol 1998;40:417-420.

7 Datt V, Virmani S, Malik I, Agarwal S, Joshi CS, Dhingra A, Dutta R, Tomar AS: Irreversible loss of vision in a paediatric patient due to occipital infarction after cardiopulmonary bypass. Ann Card Anaesth 2012;15:8890.

8 Muthusamy R, Sriram R, Dunn B: Percutaneous balloon pulmonary valvuloplasty in sickle cell anemia: a case report. Cathet Cardiovasc Diagn 1990;21:252-254.

9 Naess H, Waje-Andreassen U, Thomassen L: Occipital lobe infarctions are different. Vasc Health Risk Manag 2007;3:413-415.

10 Bova SM, Giovenzana A, Signorini S, La Piana R, Uggetti C, Bianchi PE, Fazzi E: Recovery of visual functions after early acquired occipital damage. Dev Med Child Neurol 2008;50:311-315.

-11 Spear P: Plasticity following neonatal visual cortex damage in cats. Can J Physiol Pharmacol 1995;73:13891397.

$\$ 12$ Jacobson J, Bohn D: Severe hypernatremic dehydration and hyperkalemia in an infant with gastroenteritis secondary to rotavirus. Ann Emerg Med 1993;22:1630-1632.

$\checkmark 13$ Jongen JC, Franke CL, Soeterboek AA, Versteege CW, Ramos LM, van Gijn J: Blood supply of the posterior cerebral artery by the carotid system on angiograms. J Neurol 2002;249:455-460. 


\section{Case Reports in \\ Ophthalmology}

\begin{tabular}{l|l}
\hline \multicolumn{2}{l}{ Case Rep Ophthalmol 2015;6:106-109 } \\
\hline DOI: 10.1159/000381258 & $\begin{array}{l}\text { ○ 2015 S. Karger AG, Basel } \\
\text { www.karger.com/cop }\end{array}$ \\
\hline
\end{tabular}

Mansour et al.: Irreversible Loss of Vision in a Child due to Occipital Infarction after Gastroenteritis

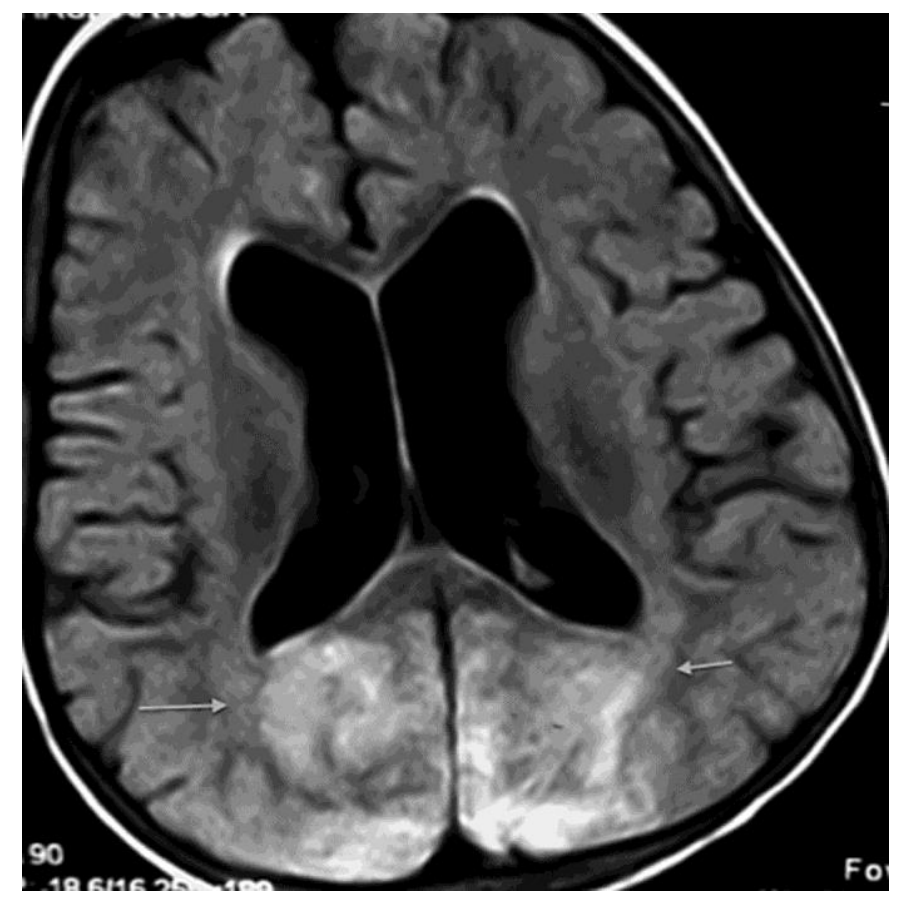

Fig. 1. MRI of the brain upon admission: axial FLAIR image at the level of the occipital region showing symmetric high-signal intensity changes involving the cortical gray matter and the subcortical white matter of both occipital lobes. A prominent ventricular dilatation is also noted. 